\title{
ANALYTICAL MODEL TRACING DEFORMATIONS IN MULTISTOREY LARGE TIMBER PANEL BUILDING
}

\author{
Jaroslaw MALESZA @1 ${ }^{*}$, Czeslaw MIEDZIALOWSKI(12), Leonas USTINOVICHIUS@3 \\ 1, ${ }^{2}$ Faculty of Civil and Environmental Engineering, Bialystok University of Technology, Bialystok, Poland \\ ${ }^{3}$ Faculty of Management, International China and Central-Eastern Europe Institute of Logistics and \\ Service Science, Bialystok University of Technology, Bialystok, Poland
}

Received 06 April 2018; accepted 26 November 2018

\begin{abstract}
This paper deals with the deformation characteristics of wood-framed residential, small commercial and hotel buildings with sheathing. Recent building structures are based on large panel or modular technology, where elements in the form of diaphragms or modules are constructed in an industrial plant and then transported to the site for assembly. The document presents diagrams of building assembly and technologies for realization. The significant influence of excessive vertical deformations in multistorey wood-framed buildings on their performance and serviceability is underlined. These deformations are caused by different factors which are identified and analytically described. The paper outlines the analytically complex model for the evaluation and control of deformations in the design, construction and exploitation of multistorey wood-framed buildings. An example of the application of the proposed analytical model at the design stage concludes the paper.
\end{abstract}

Keywords: multistorey wood-framed building, prefabrication, shrinkage, vertical deformation, analytical model.

\section{Introduction}

A significant number of constructed buildings are realized in wood-framed technology. Typical cross-sections of the wall and floor diaphragms for buildings constructed using the wood-frame with sheathing technology contain posts and joists of solid wood and sheathing of wood-derived board.

The traditional wood building technology using light wood-frames with sheathing is currently changing to a large panel method of construction. The walls, floors and roof panels are constructed at a plant in the form of large diaphragms or three-dimensional modules.

Elements constructed in the factory are then transported to the site, often at a long distance with several reloadings using varying forms of transport, including trucks and sometime ships, before final assembly, as shown in Figure 1.

Prefabrication ensures better quality of the final product and it controls essential parameters like the precision, fitting and quality of the construction, with limited moisture content in the component building diaphragms and in the modules (Malesza, 2017; Gunduz \& Yahy, 2018; Pang \& Rosowsky, 2009). This method of construction also makes
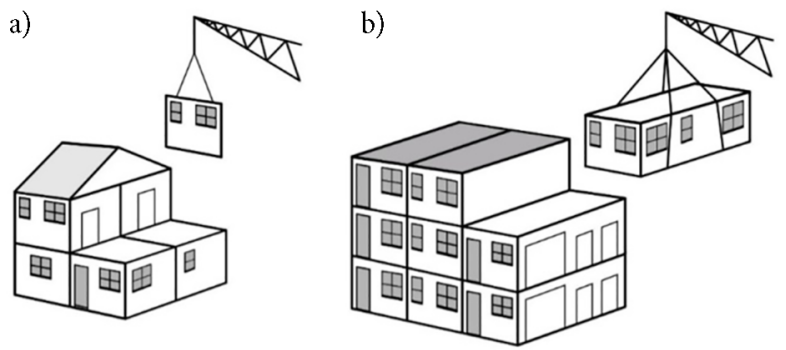

c)
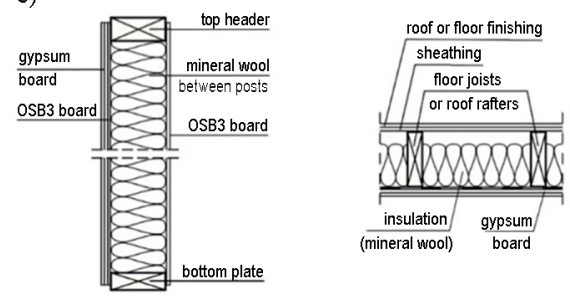

Figure 1. Assembly of structural elements at the site: a - large panels, walls and floor diaphragms; $b$ - modular 3D elements; c - cross-section of structural wall panel and floor diaphragm, elements in the wood-framed technology with sheathing

${ }^{\star}$ Corresponding author. E-mail: j.malesza@pb.edu.pl 
a)

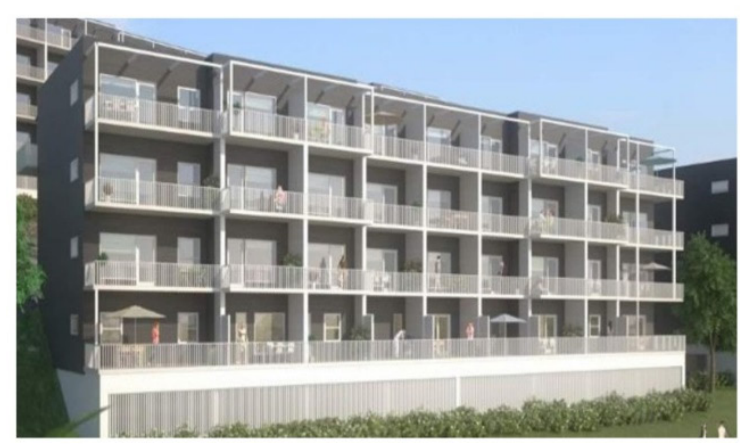

b)

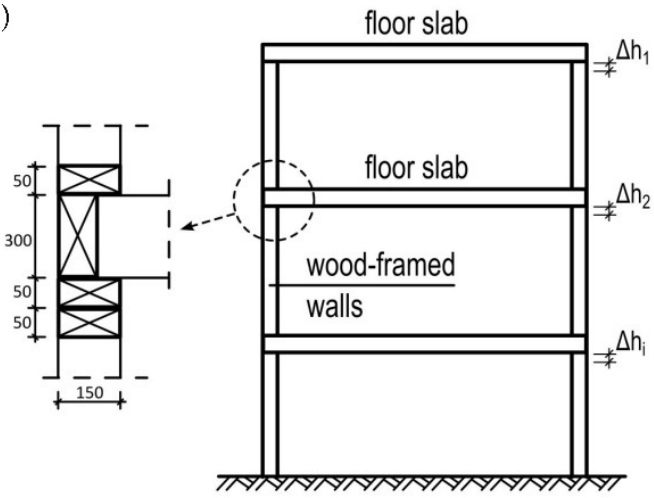

Figure 2. Multistorey large panel building: $\mathrm{a}$ - constructed building; $\mathrm{b}$ - assembly phase of wooden building

it possible to form the required thermal and acoustic parameters of a building (Jerónimo Silvestre, Antunes, \& Leal Filho, 2018). In Polish domestic experience, residential buildings are constructed using large panel technology, while multifamily and multistorey blocks of three- to fivestorey flats are constructed using the modular technology shown in Figure 2.

The foundations, basement, staircases and shafts of lifts are usually constructed in reinforced concrete, steel or masonry structures as separate parts of a building. Limited access and the costs of building sites in towns lead to a tendency to construct high six-, eight-storey and higher multifamily buildings also in wood technology. This practice creates new challenges and problems with their exploitation (NAHB, 2002; Cheung, 2000; CMHC, 2003; Chen, Chui, Ni, \& Xu, 2014; Pei, van de Lindt, Wehbe, \& Liu, 2013; Wang, Rosowsky, \& Pang, 2010).

Deformations arise in the process of constructing prefabricated wood-framed buildings when the panel elements are constructed at the plant, in the transport and assembly on site, and finally within the exploitation period (Strauss et al., 2017; Kikolski, 2016; Zhou, Ni, \& Chui, 2017). These deformations are increasing greatly, exceeding the serviceability limit state foreseen for wood-framed buildings. The basic stages of construction influencing the final deformations are presented in Figure 3.

Excessive vertical deformations in wood-framed buildings cause significant problems for inhabitants, and nondeforming staircases and their stabilized levels create differences in access, leading to difficulties closing doors and causing cracks in finishes. Significant vertical displacement appears in buildings with more than three storeys due to the drying process in the wood, which causes shrinkage, and it is additionally increased as a result of compression perpendicular to the grain (Thompson, 2015; Wallace, Cheung, \& Williamson, 2005). Typical wood-framed hori-

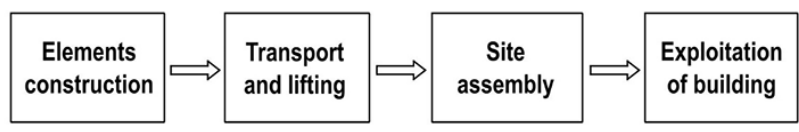

Figure 3. Construction phases of wood-framed large panel buildings zontally placed elements of cross-section $80 \times 160 \mathrm{~mm}$ lose $0.66 \mathrm{~mm}$ in thickness after two years of drying. A four-storey building loses 30.16 to $76.20 \mathrm{~mm}$ in height as a result of shrinkage (Burch \& Thomas, 1991). In the IBC 2012 International Code Council, buildings higher than three storeys should be analyzed for shrinkage at the design stage (Thompson, 2015). Shrinkage induces changes in the crosssectional dimensions of the solid wood elements built in the walls and floors. Shrinkage in a multistorey structure in the platform or modular system of construction leads to buckling of elements under compression and cracks in gypsum board finishes. Differences in shrinkage develop additional deformations compared to staircases, terraces and shafts if these were constructed in solid RC, masonry or steel technology. The cumulative effect of shrinkage in multistorey buildings is uncomfortable and very evident for inhabitants (Martin \& Anderson, 2010, 2012).

Compression perpendicular to the grain in wood has a significant effect on the ultimate serviceability of a structure (Breyer, 1993; Blass \& Gorlacher, 2004). Axially loaded vertical element acting on a horizontally placed timber plate creates compression perpendicular to the grain and causes its displacement. In buildings with more than three storeys, an element loaded perpendicular to the grain finally undergoes immediate and long-term deformation (Leicester, Fordham, \& Breitinger, 2011; Korin, 2011; Sandovic, Juozapaitis, \& Gribniak, 2017). Two percent deformations were assumed and proposed in Basta, Gupta, Leichti, and Sinha (2012) to evaluate the limit values (in NDS National Design Specifications) of stressing perpendicular to the grain.

This strain indicates that deformations under stress perpendicular to the grain develop $2 \mathrm{~mm}$ displacements per $100 \mathrm{~mm}$ height of horizontally placed elements. The number of these elements in a multistorey building is significantly large.

Deformations appearing as a result of loading and of altering the moisture content in wood must not exceed the limit values, taking into account the possibility of failures of internal finishes and considering also the functional and aesthetic requirements. Closure of fissures (clearance) in the timber element connections under compression stress 
also causes the increase of deformations (Basta et al., 2012; Dong \& Sun, 2017; Ren, Deng, Jin, Yang, \& Liu, 2017).

As it comes from literature review the main source of vertical deformation in the wood framed buildings has been examined as a result of wood shrinkage.

Vertical deformations of multistorey buildings are influenced by different factors, as found from several analyses. However, there is still a need to evaluate the homogeneous and complex methodology used for analyzing these deformations. The paper identifies the factors and parameters influencing vertical deformations and proposes a complex analytical model for analysis of these deformations. The proposed model can be used for the control of deformations in the design, construction and exploitation of wooden multistorey buildings.

It is presented in the paper additional effects in the form of deformations generated from perpendicular to the grain compression, clearance closing under loading, deformations within the transportation, settlement deformation as well as the influence of time. There is presented proposal of complex analytical model of vertical deformation computation in the wood framed buildings referring to the known formulae calculating particular influences.

\section{Characteristics of wood and its influence on deformation in buildings}

Wood has a cellular structure, where longitudinally placed parallel to the log cells create the structure of the material. They ensure the transport of water, the metabolic process, and they build the wood's structure in growing trees. Bundles of cells are placed parallel to the grain of the log, which causes varying strength properties depending on their direction, whether longitudinal or perpendicular to the grain (Kozakiewicz \& Krzosek, 2013; Dzbeński \& Kozakiewicz, 2004). Tests of wood strength properties are conducted in varying directions: parallel to the grains, perpendicular to the grain direction, or at an angle of $45^{\circ}$ to the annual rings. The elasticity modulus $E$ of softwood (coniferous) and hardwood (deciduous) depends on the angle $\alpha$ between the direction of the grain and the loading direction (Neuhaus, 2004; Simpson, 1999).

Wood's structural parameters are strongly dependent on the moisture content. The minimum moisture content of thoroughly air-dried lumber is $12-15 \%$. In kiln-dried hardwood, the moisture content will usually be less than $10 \%$.

The shrinkage effect is a natural consequence of moisture loss from the wood. The inverse effect caused by increased moisture content generates swelling. Shrinkage and swelling of wood are time-dependent processes. Shrinkage depends on both the moisture content in the wood and the environmental humidity.

The ratio indicating shrinkage depends on the kind of wood used for timber elements. It is preferable to use kilndried lumber in structures to decrease the effect of shrinkage. Dimensional changes under shrinkage and swelling have linear tendencies under varying moisture content from 5 to 20\% (Simpson, 1999).

The change of these dimensions can be evaluated from the following Eqn (1):

$$
\Delta h_{w}=\frac{\beta}{100} \cdot\left(W_{2}-W_{1}\right) \cdot\left(h_{1}+h_{2}+\cdots+h_{b}\right),
$$

where: $h_{1}, h_{2}, h_{b}$ are the transverse cross-section dimensions (thickness) under corresponding moisture $W_{1}$ and $W_{2}$, while ratio $\beta$ is the swelling (positive) or shrinkage (negative).

In the case of timber not coming from a special kind of wood, its shrinkage and swelling characteristics are known and an approximation approach can be used for the analysis of deformations. The coefficient of longitudinal changes $\beta_{0}$ has no significant influence on displacements, while $\beta_{90}$, representing transverse changes in dimensions, should be considered in the design of structures. Most of the wood species used for engineering purposes, like spruce, pine, fir, larch, oak, and poplar, indicate $\beta_{0}=0.01$ and $\beta_{90}=0.2$, where $\beta$ is the proportional change of dimensions corresponding to $1 \%$ of moisture content change. For hardwood species like beech, the parameter is taken as the value $\beta_{90}=0.3$. In the case of a constrained element working in a structural system, the parameter $\beta_{0}=0.1$ is recommended (Neuhaus, 2004; Kozakiewicz \& Krzosek, 2013; Simpson, 1999).The intensity of shrinkage depends on the dimensions of the cross-section, and in analyses the values in the tangential direction are taken as $6-13 \%$, in the radial direction 3-5\%, and longitudinally to the grain 0.1-0.8\% (Miedzialowski \& Malesza, 2006; Dzbeński \& Kozakiewicz, 2004).

Environmental factors or air-conditioning in a building significantly influence shrinkage. The total shrinkage in the traditional system of wood-framed building construction is computed as the sum of the effects for horizontally placed timber elements in floors and walls, plates in walls, ties and floor joists, as shown in Figure 4.

The combined effect of shrinkage is the result of analysis of all the horizontally placed solid wood elements used in a building structure. Longitudinal shrinkage is neglected in the analysis, because its value is estimated as $1 / 40$ of the shrinkage value perpendicular to the grain direction. In the USA, the Western Wood Products Association gives recommendations on the evaluation of displacements as a result of wood shrinkage at the design stage of a structure.

a)

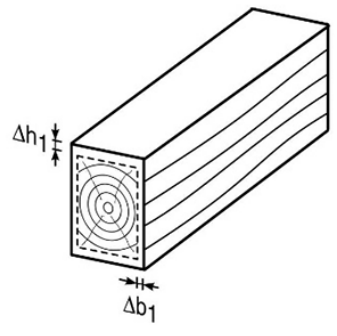

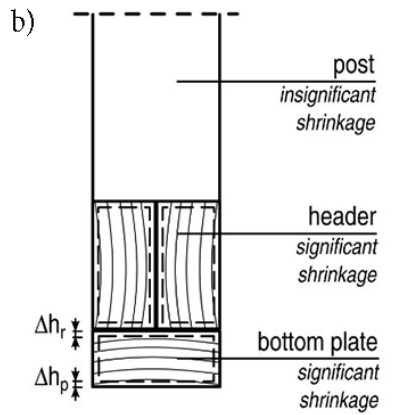

Figure 4. Shrinkage in wood: $\mathrm{a}$ - in single element; $\mathrm{b}$ - in joint connecting different elements 
a)

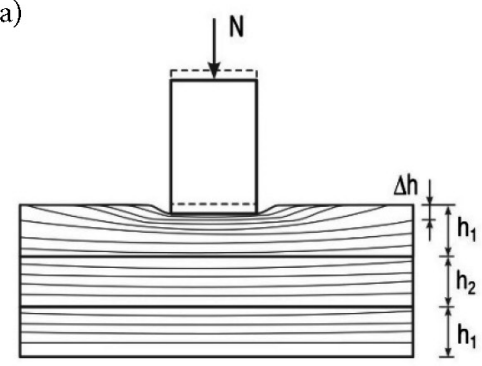

b)

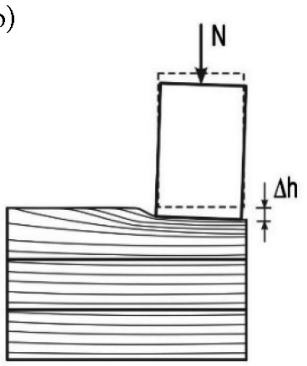

c)

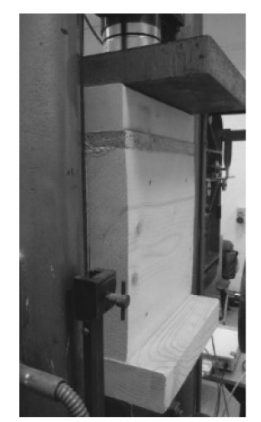

Figure 5. Deformation under compression and contact pressure: $\mathrm{a}$ - for interior posts; $\mathrm{b}$ - for terminal posts; $\mathrm{c}$ - evaluation of perpendicular to grain deformation of module floor elements in test

Panelizing and prefabrication of structural elements allow a reduction of the estimated effects of shrinkage of correctly selected and suitably stored lumber.

Lumber used in construction should present the required moisture content corresponding to the relative environmental humidity in order to minimize the problem of moisture change in the wood. The moisture content in wood used in a timber structure must not exceed $20 \%$. Wood also indicates varying elastic parameters depending on the direction of load acting on the structure. In the direction perpendicular to the grain, the deformability is 16 times greater than in the longitudinal direction. Deformation of horizontally placed solid wood elements under compression in that direction should be analyzed; the effects are shown in Figures 5a and 5b.

Deformations are computed from the following Eqn (2):

$$
\Delta h_{c, 90}=\frac{\sigma_{c, 90, k}}{E_{90, \text { mean }}} \cdot \sum h_{i},
$$

where: $\sigma_{c, 90, k}$ - compression stress under characteristic loadings perpendicular to the grain; $E_{90, \text { mean }}$ - mean elastic modulus for the direction of loading perpendicular to the grain, usually 36 times less than $E_{0, \text { mean }} ; h_{i}$ - thickness of horizontally placed timber elements.

In the assembly of layers, for example in nodes stresses (loadings) are transmitted to adjoining elements throughout contact surfaces, while stresses inside of elements are propagated according to standard areas of distribution.

In the direction along the grain for vertically loaded posts and columns, the deformations are neglected as a result of the much higher modulus of elasticity for that direction.

Experimental test on compression perpendicular to the grain of a sector of the module floor structure is presented in Figure 5c. It was found under the test that in element of $422 \mathrm{~mm}$ total height containing three joined components with the grains situated perpendicular to the load direction, the stage of clearance elimination composes at about $25 \%$ of total elastic deformation. Remaining $75 \%$ of deformation results from static compression perpendicular to the grain direction.

\section{Analytical model evaluating deformation in buildings}

The analytical model (Jiang et al., 2016) for evaluating the growth of deformations in buildings should include all phases of their formation, including (Kretschmann, 1997):

- source of lumber; place, age, kind of wood;

- cutting out of wooden elements from logs, and the drying process;

- transport of lumber and storage;

- design of wood-framed diaphragms or modules, sheathing boards, fasteners;

- construction process and prefabrication in the plant;

- operational transport of element;

- transport of panelised diaphragms or modules to the site for assembly;

- construction of basement and foundations;

- assembly of large panels or modules in the building structure, interconnecting layers and joints at the site;

- time of exploitation.

In all these phases, it is required to consider the deformations that may arise and influence the final building deformation.

The following parameters have an influence on the deformation:

- properties of the wood and its mechanical and strength parameters; moisture content, wood density; orientation of annual (growth) rings in the cross-section of structural elements;

- initial deformations and variation of moisture content in wooden profiles in transport and storage;

- fitting the planes of element faces and sub-elements;

- deformations arising in the phase of operational transport;

- deformations and varying moisture content in the phase of transporting elements to the site of assembly;

- deformation of constructed RC foundations or basement;

- deformation in the assembly phase as a result of using varying inter-layers and interconnections;

- deformations and varying moisture content in elements within the period of exploitation. 


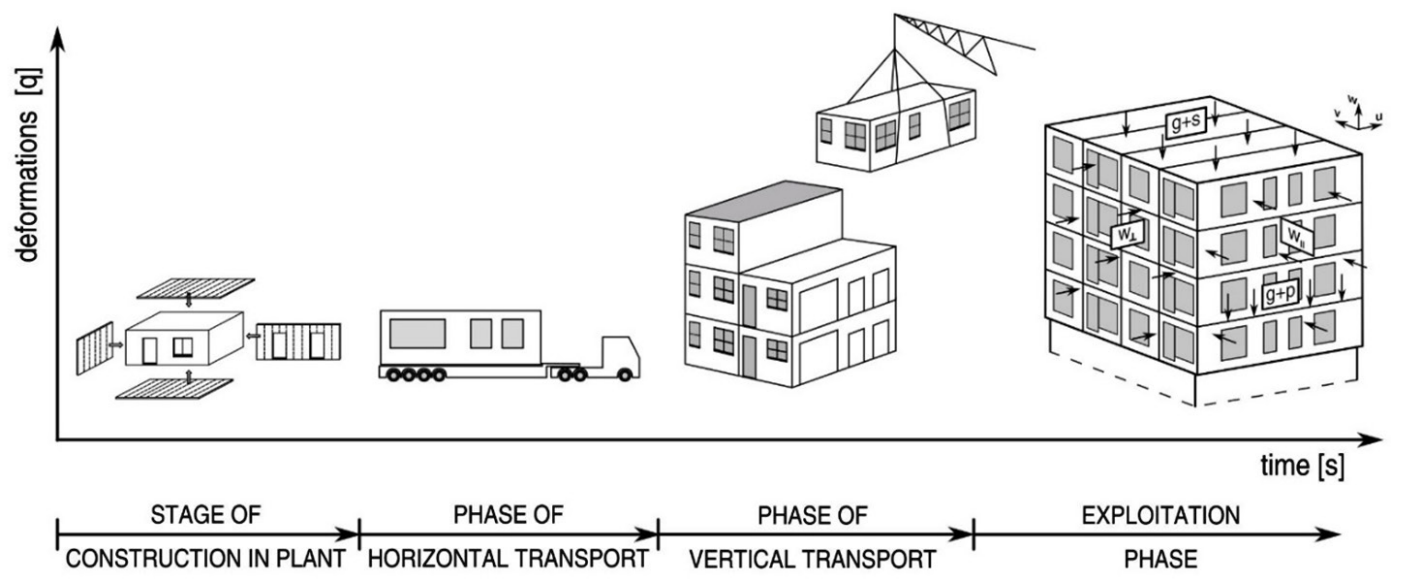

Figure 6. Stages of industrialized (in the plant) building construction

During the time of construction and exploitation, all the deformations arise from mechanical and physical actions, finally forming the resulting deformations in the building, as shown in Figure 6.

The analytical model is built in the form of the sum of influencing actions giving the final building deformations:

- deformations of sub-base soil in the form of settlement displacements: $\Delta d_{g}$;

- deformation of foundations and basement: $\Delta d_{p}$;

- deformations in transport: $\Delta d_{t}$;

- immediate deformations of structure assemblies: fault clearance, deformations as a result of strain under normal stressing and stressing perpendicular to the grain: $\Delta d_{d}$;

- deformations produced in time: shrinkage, creep, corrosion of elements.

The magnitude of deformations can be described analytically with the following Eqn (3):

$$
\Delta d=\left(\Delta d_{g}+\Delta d_{p}+\Delta d_{t}+\Delta d_{d}\right) \cdot \alpha_{t}
$$

where $\alpha_{t}$ represents the effects induced during the exploitation time.

These deformations in building practice are significantly high in the vertical direction, so making the allowance for the effect of time, all the components of formula (3) can be converted into the Eqn (4):

$$
\Delta h=\Delta h_{g} \cdot \alpha_{t}^{g}+\Delta h_{p} \cdot \alpha_{t}^{p}+\Delta h_{t} \cdot \alpha_{t}^{t}+\Delta h_{d} \cdot \alpha_{t}^{d} .
$$

a)
The sub-base deformation in the form of soil settlement is computed according to the known formulae of soil mechanics. Deformations of the basement or foundations are calculated according to the requirements of the concrete structure elements and their deflection of the floor slab over the basement or masonry structure. Deformations in transport, as shown in Figure 7, are determined by applying surveying methods when the structural elements are delivered to the site, before their handling, lifting and assembly in the building with large panels, wall and floor diaphragms, and modules (European Committee for Standardization (CEN), 2004).

The timber framing deformations, having a decisive influence on all displacements, are proposed to be evaluated from the following Eqn (5):

$$
\Delta h_{d} \cdot \alpha_{t}=\Delta h_{l}+\Delta h_{\text {fin }}+\Delta h_{s}
$$

where: $\Delta h_{l}$ - deformation as a result of gaps and clearance between timber elements, in values taken from experimental tests or practice; $\Delta h_{f i n}$ - deformation as a result of compression in wood; posts, horizontal plates and joists (perpendicular to the grain) as well as all distance spacers and also the influence of time:

$$
\Delta h_{\text {fin }}=\Delta h_{\text {inst }}+\Delta h_{\text {creep }}
$$

$\Delta h_{\text {inst }}$ - immediate deformation as a result of posts and joists-plates horizontal elements obtained from the Eqn (7):

$$
\Delta h_{\text {inst }}=\frac{\sigma_{c, 0, k}}{E_{0, \text { mean }}} \cdot h_{s}+\frac{\sigma_{c, 90, k}}{E_{90, \text { mean }}} \cdot h_{b}+\sum \frac{\sigma_{c}}{E_{w p}} \cdot h_{w p},
$$

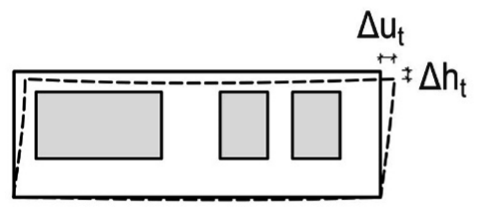

b)

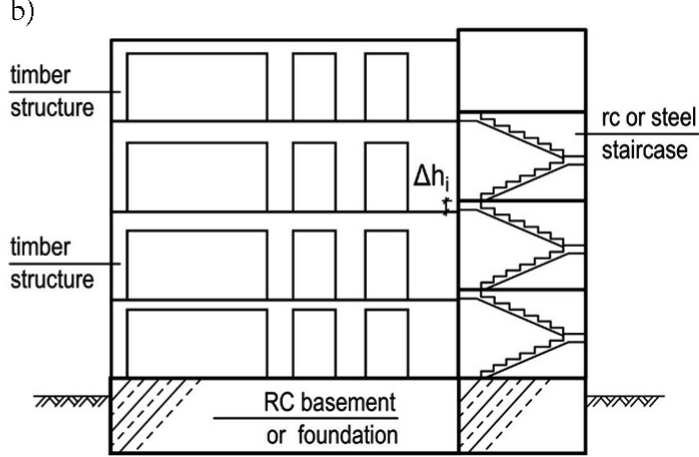

Figure 7. Transport deformation: $\mathrm{a}$ - of module; $\mathrm{b}$ - in building 
where $\sigma_{c}$ is the compression stress in the cross-sections of posts and in the distance spacers between elements; $\sigma_{c, 90, k}$ is the bearing stress; $h_{s}$ is the height of posts; $h_{b}$ is the height of the joists and horizontal plates crosssections;

$h_{w p}$ is the thickness of distance spacers; $\Delta h_{\text {creep }}$ is deformation as a result of the creep process evaluated from the Eqn (8):

$$
\Delta h_{\text {creep }}=\Delta h_{\text {inst }} \cdot \psi_{21} \cdot k_{\text {def }},
$$

where $\psi_{21}$ is the reduction factor of the characteristic value of variable action and $k_{d e f}$ is the factor representing the growth of deformation due to creep.

Taking into account Eqns (4) and (6), the formula takes the form:

$$
\Delta h_{\text {fin }}=\Delta h_{\text {inst }} \cdot\left(1+\psi_{21} \cdot k_{\text {def }}\right) \text {, }
$$

where $\Delta h_{s}$ - deformation under shrinkage of timber elements, which can be described by the Eqn (10):

$$
\Delta h_{s}=\Delta W_{b} \cdot \beta^{b} \cdot \Sigma h_{b}+\Delta W_{s} \cdot \beta^{s} \cdot h_{s},
$$

where $\Delta W$ is the change in moisture content of wood in floor joists, horizontal plates and posts, while $\beta$ is a parameter of moisture deformation transversally and longitudinally.

\section{Estimation and control of deformations}

Strategy of calculation and deformation controlling in structure shall take into account condition of practical realization of the wood-framed buildings and effects significantly deciding on vertical deformations of structure. There can be also used wood demonstrating lower shrinkage deformation like glulam wood.

The basements, foundations and staircases in woodframed buildings with sheathing are usually constructed in the form of monolithic RC or masonry structures. Displacements in the wood-framed storey structure create hazards in the exploitation of the timber structure due to higher deformations of wood than the rigid structure of the concrete and masonry elements.

Deformations during transport, with the influence of time effects, should be evaluated before assembling the elements of the building. It should be noted that some of the longitudinal deformations of posts under compression and deformation from longitudinal shrinkage are neglected in practical analysis. Deformations of the interlaying thin plates also have a negligible influence on the displacements. Finally, Eqn (4) describing the practical deformation can be presented in the following form:

$$
\begin{gathered}
\Delta h=\Delta h_{i}=\Delta h_{t}+\sum \Delta h_{l}+\left(\frac{\sigma_{c, 90, k}}{E_{90, \text { mean }}} \cdot \sum h_{b}\right) . \\
\left(1+\psi_{21} \cdot k_{\text {def }}\right)+\Delta W_{b} \cdot \beta^{b} \cdot \sum h_{b} .
\end{gathered}
$$

The growth of deformations from the lowest to the highest storey of the building is presented in Figure 8.
The deformations at each level of the building are summed up according to the following Eqn (12):

$$
\Delta H_{i}=\sum_{1}^{n} \Delta h_{i}
$$

where $n$ - number of levels where displacements are estimated.

In the case of varying deformations obtained as a result of analysis in the building plane, equalization of the resulting displacements (redistribution) should be conducted as the influence of building storey stiffness. The finite element method, either averaging the displacements over the building area or using the analogy of a beam on an elastic subbase, can be used.

The deformation is divided into immediate and longterm components, considering the final settlement of the storey height and the evaluation of the thickness of the finishing layers at each storey of the building, as in the following Eqns:

$$
\begin{aligned}
& \Delta h_{i}^{\text {inst }}=\Delta h_{t}^{i}+\sum \Delta h_{l}^{i}+\frac{\sigma_{c, 90, k}}{E_{90, \text { mean }}} \cdot \sum h_{b}^{i}+\overline{\Delta W} \cdot \beta^{b} \cdot \sum h_{b}^{i} ; \\
& \Delta h_{i}^{\text {time }}=\frac{\sigma_{c, 90, k}}{E_{90, \text { mean }}} \cdot \sum h_{b}^{i} \cdot \eta+\overline{\overline{\Delta W}} \cdot \beta^{b} \cdot \sum h_{b}^{i},
\end{aligned}
$$

where: $\overline{\Delta W}$ - change in moisture content in wood used for timber structure to the time of building settlement; $\eta$ - factor determining the long-term part of deformation under compression and compression perpendicular to the grain:

$$
\eta=\Sigma\left(\frac{q^{m}}{\sum q^{m}} \cdot \psi_{21}^{m} \cdot k_{d e f}^{m}\right)
$$

where $q_{m}$ - live loadings including snow load, wind load and live load. In Polish standards the value of $\eta$ can be taken as 0.52 .

$\overline{\Delta W}$ - change of moisture in wood from settlement of the building to the time of stabilizing the moisture in the wood.

The sum of deformations of the $i$-th storey is calculated from the Eqn (16):

$$
\Delta H_{i}=\sum_{1}^{n} \Delta h_{i}^{\text {inst } t \text { time }}=\sum_{1}^{n} \Delta h_{i}^{\text {inst }}+\sum_{i}^{n} \Delta h_{i}^{\text {time }} .
$$

The immediate deformations evaluated at the design stage enable adjustment of the levels of stores.

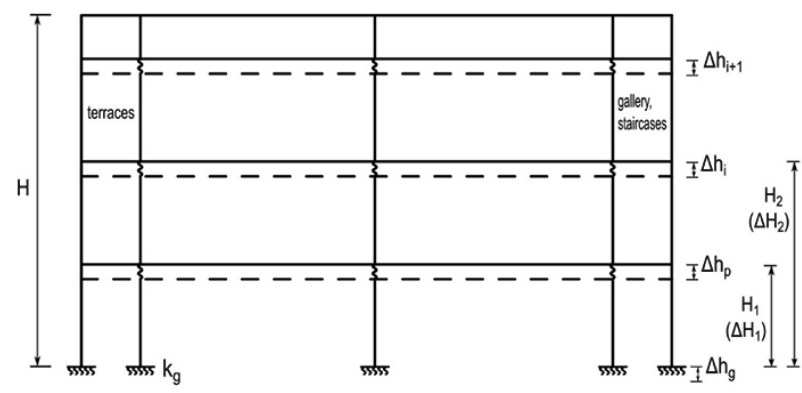

Figure 8. Growth of components deformations 


\section{Application example of analytical model}

A three-storey building with the schematic cross-section at the floor levels of each storey as shown in Figure 9 was used in the analysis.

As shown in Figure 9, the sum of the horizontal elements, wall plates and floor joist thicknesses is equal to $\sum h_{b}^{i}=450 \mathrm{~mm}$. The following assumptions were made:

- modulus of elasticity perpendicular to grain: $E_{90, \text { mean }}=370 \mathrm{MPa}$;

- moisture content changes during the time of settling $\overline{\Delta W}=4 \%$;

- moisture content change after settling $\overline{\overline{\Delta W}}=8 \%$;

- coefficient of moisture deformation $\beta^{b}=0.10 \% / \% \Delta W$;

- transport deformation neglected $\Delta h_{t}=0$;

- average loading to wall horizontal plate $35.00 \mathrm{kN} / \mathrm{m}$;

- coefficient considering increase of deformation with time $\eta=0.52$.

The cross-sectional dimensions of the wall posts are $50 \times 150 \mathrm{~mm}$ with spacing $600 \mathrm{~mm}$. The compression stress perpendicular to the grain is calculated involving an effective contact length $l_{e f}=50+30+30=110 \mathrm{~mm}$.

$$
\sigma_{c, 90, k}=\frac{35.00 \cdot 10^{3} \cdot 0.60}{110 \cdot 150}=1.27 \frac{\mathrm{N}}{\mathrm{mm}^{2}},
$$

where the maximum gaps (clearance) between elements is taken as $0.4 \mathrm{~mm}$.

Finally, the vertical deformations for the three-storey building reach the value:

$\Delta h_{i}^{\text {inst. }}=3\left(3 \cdot 0.4+\frac{1.27}{370} \cdot 450+4 \cdot \frac{0.10}{100} \cdot 450\right)=13.63 \mathrm{~mm} ;$

$\Delta h_{i}^{\text {time. }}=3\left(\frac{1.27}{370} \cdot 450 \cdot 0.52+8 \cdot \frac{0.10}{100} \cdot 450\right)=13.21 \mathrm{~mm}$.

The sum of vertical deformations is:

$\Delta h_{i}=13.63+13.21=26.84 \mathrm{~mm}$.

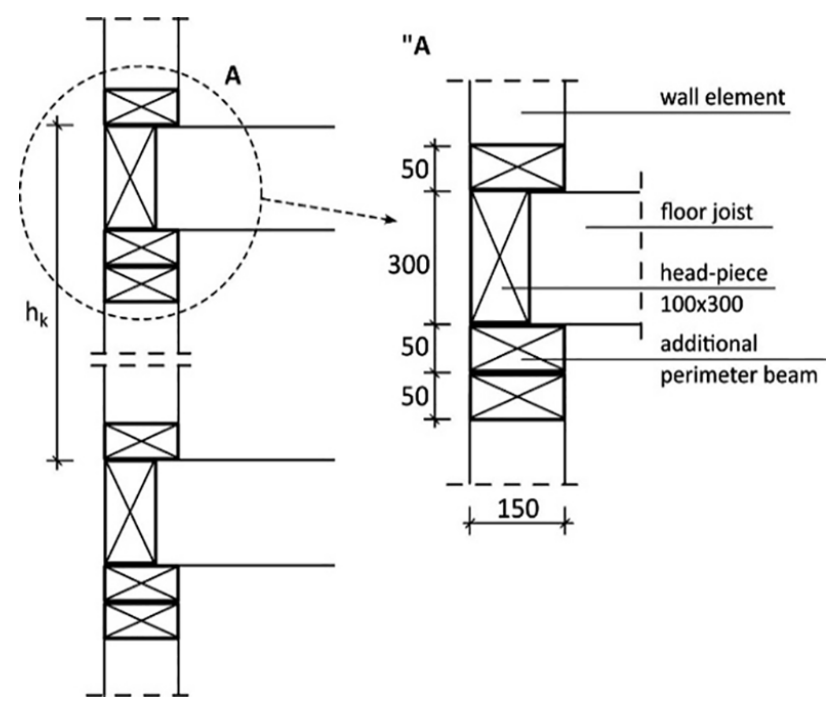

Figure 9. Schematic cross-section of single storey in analysed building
A wall with an opening width of $2.40 \mathrm{~m}$ generates deformation under the increased post cross-section of $120 \times 150 \mathrm{~mm}$ supporting the header, which has the value:

$\sigma_{c, 90, k}=\frac{35.00 \cdot 10^{3} \cdot(0.3+1.2)}{(120+30+30) \cdot 150}=1.94 \mathrm{~N} / \mathrm{mm}^{2} ;$

$\Delta h_{i}^{\text {inst. }}=3\left(3 \cdot 0.4+\frac{1.94}{370} \cdot 450+4 \cdot \frac{0.10}{100} \cdot 450\right)=16.08 \mathrm{~mm} ;$

$\Delta h_{i}^{\text {time }}=3\left(\frac{1.94}{370} \cdot 450 \cdot 0.52+8 \cdot \frac{0.10}{100} \cdot 450\right)=14.48 \mathrm{~mm} ;$

$\Delta h_{i}=16.08+14.48=30.56 \mathrm{~mm}$.

The obtained deformation result significantly exceeds the typically accepted dimensional clearance in building construction.

\section{Conclusions}

The deformations under compression of structural elements, their shrinkage, and gaps between elements composing the structure collectively exert a significant influence on the serviceability limit state in the form of vertical displacements in timber structures, taking into account also the influence of time. The paper is focused on the identification and analytical description of all the factors influencing these vertical deformations, specifying procedures for evaluating the deformations under compression, shrinkage, and gaps appearing between the structural elements composing the building. The evaluated deformations are significantly large in the direction perpendicular to the grain in horizontally placed elements. These deformations influence the function and behaviour of the structure, degrading the comfort of exploitation.

A complex model for the analysis and control of deformations is presented and illustrated with an analytical example.

The paper presents a model and procedure for calculating vertical deformations in buildings. It also recommends the evaluation of immediate and long-term deformations. This provides the possibility to reduce the immediate deformations at the design and construction stages. Longterm deformations are to be evaluated and foreseen at the design stage and then a technical solution can be exploited to control this process.

\section{Acknowledgements}

The paper was prepared at Bialystok University of Technology within the framework of the S/WBiIS/1/2018 project sponsored by the Ministry of Science and Higher Education.

\section{Disclosure statement}

Authors do not have any competing financial, professional, or personal interests from other. 


\section{References}

Basta, C. T., Gupta, R., Leichti, R. J., \& Sinha, A. (2012). Applications of perpendicular-to-grain compression behavior in real wood construction assemblies. Wood and Fiber Science, 42(2), 155-167.

Blass, H. J., \& Gorlacher, R. (2004). Compression perpendicular to grain. In $8^{\text {th }}$ World Conference on Timber Engineering: WCTE 2004. Lahti. Finland.

Breyer, D. E. (1993). Design of wood structures ( $3^{\text {rd }}$ ed.). New York: McGraw-Hill.

Burch, D. M., \& Thomas, W. C. (1991). An analysis of moisture accumulation in a wood frame wall subjected to winter climate (Final Report, U.S. National Institute of Standard and Technology). Gaithersburg, MD.

Canada Mortgage and Housing Corporation (CMHC). (2003). Building technology - Wood-framed envelopes. Canada.

Chen, Z., Chui, Y. H., Ni, C., \& Xu, J. (2014). Seismic response of midrise light wood-frame buildings with portal frames. Journal of Structural Engineering, 140(8).

https://doi.org/10.1061/(ASCE)ST.1943-541X.0000882

Cheung, K. C. K. (2000). Multi story wood-framed construction. Western Wood Products Association, USA.

Dong, J., \& Sun, W. (2017). Internal co-seismic deformation and curvature effect based on an analytical approach. Earthquake Science, 30(1), 47-56. https://doi.org/10.1007/s11589-017-0176-5

Dzbeński, W., \& Kozakiewicz, P. (2004). Wood and wood derivatives used in timber structures. In Conference WPPK Ustroń, Bielsko-Biała, Poland (in Polish).

European Committee for Standardization (CEN). (2004). Design of Timber Structures. Part 1-1: General-Common Rules and Rules for Buildings (EN 1995-1-1).

Gunduz, M., \& Yahy, A. M. A. (2018). Analysis of project success factors in construction industry. Technological and Economic Development of Economy, 24(1), 67-80.

https://doi.org/10.3846/20294913.2015.1074129

Jerónimo Silvestre, W., Antunes, P., \& Leal Filho, W. (2018). The corporate sustainability typology: analysing sustainability drivers and fostering sustainability at enterprises. Technological and Economic Development of Economy, 24(2), 513-533. https://doi.org/10.3846/20294913.2016.1213199

Jiang, W., Li, S., Luo, Y., Xu, S., Gong, J., \& Tu, S. T. (2016). An analytical model to predict the equivalent creep strain rate of a lattice truss panel structure. Materials Science and Engineering A - Structural Materials Properties Microstructure and Processing, 661, 152-159.

https://doi.org/10.1016/j.msea.2016.03.028

Kikolski, M. (2016). Identification of production bottlenecks with the use of plant simulation software. Economics and Management, 8(4), 103-112.

https://doi.org/10.1515/emj-2016-0038

Korin, U. (2011). Timber in compression perpendicular to grain. In Proceedings of the CIB-W-18 (Paper 23-6-1). Danish Timber Information.

Kozakiewicz, P., \& Krzosek, S. (2013). Engineering of wood materials. Warsaw: SGGW Edition (in Polish).

Kretschmann, D. E. (1997). Effect of juvenile wood on shear parallel and compression perpendicular-to-grain. Quebec: USDA Forest Service, Forest Products Laboratory.

Leicester, R. H., Fordham, H., \& Breitinger, H. (2011). Bearing strength of timber beams. In Proceedings of the CIB-W-18 (Paper 31-6-5). Danish Timber Information.
Malesza, J. (2017). Effective model for analysis of wood-framed timber structures. Archives of Civil Engineering, 63(2), 99-112. https://doi.org/10.1515/ace-2017-0019

Martin, Z., \& Anderson, E. (2012). Multistory wood framed shrinkage effect on exterior deck drainage (A case study). Structure Magazine, (April), 33-36.

https://www.structuremag.org/wp-content/uploads/CStrucPractices-Martin-Apr121.pdf

Miedzialowski, C., \& Malesza, M. (2006). Wood-framed with sheathing buildings; Bases of structure mechanics and construction problems. Studies in the Range of Engineering, 55. Edition of Bialystok University of Technology, Warsaw - Bialystok (in Polish).

National Association of Home Builders Research Center (NAHB). (2002). Advanced panelized construction. Year one progress report. Prepared for Partnership for Advancing Technology in Housing (PATH). Washington D.C., USA.

Neuhaus, H. (2004). Timber engineering handbook. Polish Technical Edition Rzeszów (in Polish).

Pang, W., \& Rosowsky, D. V. (2009). Direct displacement procedure for performance-based seismic design of mid-rise wood-framed structures. Earthquake Spectra, 25(3), 583-605. https://doi.org/10.1193/1.3158932

Pei, S., van de Lindt, J. W., Wehbe, N., \& Liu, H. (2013). Experimental study of collapse limits for wood frame shear walls. Journal of Structural Engineering, 139(9), 1489-1497. https://doi.org/10.1061/(ASCE)ST.1943-541X.0000730

Ren, J., Deng, S., Jin, Z., Yang, J., \& Liu, X. (2017). Energy method solution for the vertical deformation of longitudinally coupled prefabricated slab track. Mathematical Problems in Engineering, 2017, Article ID 8513240.

https://doi.org/10.1155/2017/8513240

Sandovic, G., Juozapaitis, A., \& Gribniak, V. (2017). Experimental and analytical investigation of deformations and stress distribution in steel bands of a two-span stress-ribbon pedestrian bridge. Mathematical Problems in Engineering, 2017, Article ID 9324520. https://doi.org/10.1155/2017/9324520

Simpson, W. T. (1999). Drying and control of moisture content and dimensional changes forest products laboratory. In Wood handbook - Wood as an engineering material. Forest Products Laboratory.

Strauss, A., Wan-Wendner, R., Vidovic, A., Zambon, I., Yu, Q., Frangopol, D. M., \& Bergmeister, K. (2017). Gamma prediction models for long-term creep deformations of prestressed concrete bridges. Journal of Civil Engineering and Management, 23(6), 681-698. https://doi.org/10.3846/13923730.2017.1335652

Thompson, D. S. (2015). Wood works, Wood Product Council Design example five-story wood-framed structure over podium slab. Lake Forest, Canada: STB Structural Engineers Inc.

Wallace, D. E., Cheung, K. C. K., \& Williamson, T. (2005). Multistory wood framed construction in the USA. NZ Timber Design Journal, 7(2), 11-23.

Wang, Y., Rosowsky, D. V., \& Pang, W. (2010). Performancebased procedure for direct displacement design of engineered wood-frame structures. Journal of Structural Engineering, 136(8), 978-988.

https://doi.org/10.1061/(ASCE)ST.1943-541X.0000188

Zhou, L., Ni, C., \& Chui, Y. H. (2017). Testing and modeling of wood-masonry hybrid wall assembly. Journal of Structural Engineering, 143(2). https://doi.org/10.1061/(ASCE)ST.1943-541X.0001654 